\title{
CAÑEDO RODRÍGUEZ, MONTSERRAT (ed.) (2013) Cosmopolíticas. Perspectivas antropológicas. Madrid: Editorial Trotta, 492 pp.
}

\author{
Jesús Sánchez Azañedo \\ Universidad Nacional de Educación a Distancia
}

De la oposición entre el pie y la arena en la orilla de la playa, surge la huella. De la fricción producida por el cálamo y el pergamino, lubricada esta por la tinta y la intención, emerge la escritura y la idea cristalizada, pero no por ello deja de ser susceptible de ser removida y renovada.

La obra que vamos a reseñar es un ejemplo fáctico de la fricción de toda una serie de ontologías políticas plurales, que en su encuentro pueden dar lugar, como en todos los sistemas complejos humanos a emergencias inesperadas.

Cuando te encuentras reunido en compañía de un pequeño grupo de antropólogos, a lo largo de una conversación distendida centrada en las personales experiencias de cada uno en sus trabajos de campo, todos y cada uno de ellos destilarán sus inercias, tanto a nivel personal como en las referencias a sus trabajos de campo.

Esta recopilación de textos de antropología política clásica y contemporánea, refleja y destila parte de los énfasis e inercias antropológicas de la compiladora. La principal, desde mi punto de vista, es pasión, pasión antropológica que se transmite en la lectura combinada de los textos. Una pasión centrada en este caso, en las diferentes formas de convivencia, que aun con intereses no comunes, y desde la fricción creativa, produce emergencias no esperadas. Pasión que enfatiza el carácter situado de las etnografías, 
proporcionando diferentes perspectivas antropológicas como forma de aprehender y de entender las diferentes realidades estudiadas. Pasión que nos plantea la compilación de textos desde un doble horizonte de sentido como hilo conductor. Por un lado el concepto de Cosmopolíticas tomado de la filósofa Isabelle Stengers, un concepto que alude a la convivencia de una serie de ontologías plurales cuyas formas de coexistencia vienen dadas por una asunción y un reconocimiento de las diferencias, que lejos de fundirse en una homogeneidad común, lo que provocan es un proceso de fricción creativa. La segunda parte del hilo conductor de la obra, son las «Perspectivas» antropológicas, refiriéndose estas al carácter situado del propio trabajo etnográfico. El cual desde una reflexividad basada en la auto-observación y la auto-descripción, implica un posicionamiento que no es ciego a la parcialidad de lo observado y de la mirada que observa.

La editora, a partir de los diecisiete textos que integran el volumen, -muchos de ellos citados continuamente en los manuales al uso de antropología política, y por primera vez traducidos al español-, transversaliza los dos hilos conductores anteriormente descritos, desde diferentes opciones o enfoques de lectura. Si individualmente cada uno de los diferentes textos nos aporta un contenido, un significado específico, en conjunto son algo más que la suma de sus partes. El conjunto de textos da opción a una variedad de rutas de lectura diferentes. Algunas ya sugeridas por la editora a partir de la división del libro en cinco grandes bloques : I- Gramáticas y lógicas de lo político, el cual incluye dos textos tan clásicos como son el de Evans-Pritchard, "El sistema político de los Nuer", y el de Louis Dumont, "El gobierno de las castas; justicia y autoridad", junto a otro de Roy Wagner, "La persona fractal" cuya vanguardia teórica nos adentra en el novedoso y todavía por explorar paradigma holográfico. II-Simbolismo, perfomance ritual y liderazgo, que contiene textos como el de Leach, "Gumlao y Gumsa", el de Gluckman, "El puente. Análisis de una situación social en la moderna Zululandia", el de Turner, "La función políticamente integradora del ritual", y el de Abner Cohen, "La mística del poder". III-Hegemonía y resistencia, compuesto por los textos de Mintz, "Historia de una plantación en Puerto Rico", de Taussig, "La ley de una tierra sin ley", de Verdery, "Aventuras antropológicas con el Mago de Oz de Rumania, 1973-1989", y de Tsing, "La selva de las colaboraciones". IV-Tecnopolíticas, incluyendo textos de Mitchell, "¿Puede hablar el mosquito?", de Raffles, "Intimidades fluviales. Amapá, 1995-1996”, y de Latour, "Objeto de las ciencias, objetividad del derecho". Por último, el quinto bloque, titulado Cosmopolíticas, que incluye textos de Descola, "Nada de política, por favor", de Viveiros de Castro, "Perspectivismo y multinaturalismo en la América indígena", y de Povinelli, “¿Escuchan las rocas? La política cultural de la aprehensión del trabajo aborigen australiano". Otra posible ruta de lectura es la temporal, la cual desde un criterio histórico nos aportará conocimiento acerca del propio devenir de la antropología política. El lapso temporal de los textos va desde los años cuarenta, hasta prácticamente hoy día. Dentro del mismo, la editora apuesta por textos tan sumamente clásicos como 
el de Max Gluckman, definitivo para el análisis situacional; el de Evans -Pritchard sobre la organización política de los nuer, el de Abner Cohen sobre la reproducción social de las élites de poder a través del ritual. O el de Victor Turner, también sobre el ritual en su función políticamente integradora y como forma catártica de el "drama social"; una de las aportaciones fundamentales de este autor que queda sumamente clarificada en este artículo. Desde una perspectiva temporal más cercana se incluyen una serie de textoscuyos autores han tenido un impacto visible de la disciplina. Entre ellos, podemos citar a Michel Taussig, quien desde la propia construcción etnográfica, tratando al mismo medio como mensaje, nos hace revivir en nuestras propias carnes y conciencias, la violencia, angustia y desasosiegos vividos por él en su estancia en Colombia, a través de su relato. Otros autores, como Viveiros de Castro, Wagner, Tsing, Descola y Latour, hacen análisis complejos, entendidos como profundos, poliédricos y muy bien informados sobre temáticas que en principio parecerían estar muy trilladas; y que, muy al contrario, están abiertas a interpretaciones de mayor calado que las hasta ahora realizadas. Tal tipo de interpretaciones más poliédricas, también caracterizan textos tan clásico como el de Edmund Leach, que describe el proceso de sucesión entre dos sistemas, "Gumlao y "Gumsa”, que como doble atractor cíclico va generando orden en un sistema mayor, basado un principio de alternancia . O el magistral texto de Louis Dumont y su exposición sobre las castas hindúes en relación con una totalidad, yo diría cosmológico-social.

Resumiendo, creo que la editora nos regala una obra fresca, nutricia, dinámica, llena de posibilidades y diferentes acercamientos de profundización en su lectura. Se puede hacer una primera lectura básica del libro, incluso de los temas complejos, gracias a la aclaratoria y explicativa introducción del volumen . A ella podremos volver a medida que progresemos en la lectura de los textos, para aclarar ideas, conceptos y enfoques que se iluminan desde su faro alumbrador. De gran ayuda son también las variadas anotaciones que la editora hace a pie de página de los diferentes textos. Incluso algunas notas van más allá del contenido inherente del propio texto, en su énfasis aclaratorio y contextualizador. Todo ello hace el texto accesible a aficionados y estudiantes de antropología, así como lecturas más profundas, poliédricas y fecundas realizadas por antropólogos más avezados en las lides disciplinares, y que hasta ahora no tenían acceso a ciertos textos traducidos al español.

Por último, si accedemos a la lectura desde el énfasis puesto por la editora en las perspectivas antropológicas, vamos a tener la oportunidad de ver, las "parcialidades" de la mirada, y lo observado; y cómo lo transmite cada autor. Especialmente intensos en esa línea me han parecido el texto de Taussig ya comentado anteriormente, y también el de Verdery . Porque es, desde una reflexividad acerca de las influencias, y de las expectativas propias en la etnografía, desde donde surge, en el mismo investigador, una visión u 
otra, según la perspectiva que use para enfocar su propio trabajo. De nuevo, la forma constructiva etnográfica de Gluckman me ha parecido magistral, en la realización de una etnografía en el transcurso de un día, y el análisis situacional que realiza. No menos interesante resulta la elaboración de Timothy Mitchell, quien muestra en el texto una capacidad inusitada para relacionar y conectar elementos, procesos, eventos y relaciones aparente inconexos, pero que forman parte de un todo más complejo, interconectado y relacionado. El broche final, en mi lectura, sería el artículo de Hugh Raffles, y su forma de mostrar desde la metáfora la mutua construcción entre la agencia y las estructuras de una forma heterocrónica: cómo el tiempo, el lugar, las estructuras, incluso la propia agencia, son trascendidos por las intimidades, afectivas de los humanos a la hora de dar rienda suelta al cariño, el afecto y el amor.

En definitiva, el lector tiene entre las manos un texto ameno y pulcramente editado que ofrece interesantes posibilidades de acercamiento a la antropología política clásica y contemporánea. 